\title{
Assessment of the Willingness of the Pregnant Women to Pay for the SMS Texts or Phone Calls for the Improvement of Prenatal and Postnatal Health Care Services Dschang Health District, West Region, Cameroon
}

Nkemngu Blake Afutendem ${ }^{1,2}$, Claude Ngwayu Nkfusai ${ }^{2,3 *}$, Vecheusi Zennobia Viyoff ${ }^{2,3}$, Franklin Nsai Sanyuy ${ }^{2,3}$, Terrence Beteck Epie ${ }^{2,4}$, Fala Bede ${ }^{2}$ and Samuel Nambile Cumber ${ }^{5,6,7}$

${ }^{1}$ Department of Public Health, Faculty of Science, University of Dschang, Cameroon

${ }^{2}$ Cameroon Baptist Convention Health Services (CBCHS), Cameroon

${ }^{3}$ Department of Microbiology and Parasitology, University of Buea, Cameroon

${ }^{4}$ Nuffield Department of Medicine, University of Oxford, United Kingdom

${ }^{5}$ Department of Public Health and Community Medicine, University of Gothenburg, Sweden

${ }^{6}$ Faculty of Health Sciences, University of Pretoria Private Bag X323, South Africa

${ }^{7}$ Faculty of Health Sciences, University of the Free State, South Africa

Submission: August 14, 2019, Published: September 10, 2019

*Corresponding author: Ngwayu Claude Nkfusai, Cameroon Baptist Convention Health Services (CBCHS), Cameroon

\begin{abstract}
Background: The term E-Health refers to the use of modern information and communication technologies (ICT) to meet needs of citizens, patients, healthcare professionals, healthcare providers, as well as policy makers. Short message service (SMS), commonly referred to as "text messaging," is a service for sending short messages of up to 160 characters (224 characters if using a 5-bit mode) to mobile devices, including cellular phones, smartphones and PDAs. This study therefore had as aim to assess of the willingness of the pregnant women to pay for the SMS texts or phone calls for the improvement of prenatal and postnatal health care services Dschang Health District, West Region, Cameroon.

Methods: This was a Cross sectional descriptive study in the Dschang Health District, West Region of Cameroon. We included all pregnant women aged 18years and above. A total of 372 pregnant women were included. This study was carried out from March to July 2016.

Result: Majority of the women that is $252(67.74 \%)$ were married, $117(31.45 \%)$ of the women affirmed being single, and $3(0.81 \%)$ were devorced. 336 (90.32\%) of the women were Christians, 28 (7.53\%) were Muslim and 8 (2.15\%) affirmed being pagans. 216 women out of the 335 (64.44\%) that responded willing to receive SMS texts and phone calls affirmed being willing to pay for the service, against $35.52 \%$.

Conclusion: This study shows that cell phones would be an acceptable approach to provide pregnancy and postpartum support to women in the Dschang health district, since most women interviewed had access to a cell phone and referred it as a desired and accepted means of communication. In this cell phone approach, free SMS messages and voice calls will be privileged over internet-based interventions.

Keywords: Pregnant women; Improvement; Prenatal and Postnatal care services; SMS; Dschang Health District; West Region; Cameroon

Abbreviations: MNCH: Maternal New-born and Child Health; DHD: Dschang Health District; PDA: Personal Digital Assistant; ANC: Antenatal Care; PNC: Postnatal Care; PMTCT: Prevention of Mother to Child Transmission; TRA: Telecommunications Regulatory Agency; SMS: Short Text Messages; ICT: Information and Communication Technologies; WHO: World Health Organization; ITN: Insecticide Treated Bed Nets; IPTp: Intermittent Preventive Treatment of Malaria During Pregnancy; STIs: Sexually transmitted infections; ATV: Anti Tetanic Vaccine; DHS: Demographic Health Survey; A2P M: Application-to-Peer Messaging; FNIH: Foundation for the National Institutes of Health; IHISM: Integrated Healthcare Information Service; AESSIMS: Acute Encephalitis Syndrome Surveillance Information Management System; PATH: Program for Appropriate Technology in Health.
\end{abstract}




\section{Introduction}

\section{Ehealth (Electronic Health)}

The term Ehealth refers to the use of modern information and communication technologies (ICT) to meet needs of citizens, patients, healthcare professionals, healthcare providers, as well as policy makers [1].

\section{MHealth (Mobile Health)}

It's a general term for the use of mobile phones and other wireless technology in medical care. The most common application of mHealth is the use of mobile phones and communication devices to educate consumers about preventive health care services [2].

\section{Prenatal Care}

Also known as antenatal care, is a type of preventive healthcare with the goal of providing regular check-ups that allow doctors or midwives to treat and prevent potential health problems throughout the course of the pregnancy while promoting healthy lifestyles that benefit both mother and child [3].

\section{Postnatal care}

Preventive care practices and routine assessments to identify and manage or refer complications for both mother and baby perfumed by a skilled professional [4].

\section{Short Message Service (SMS)}

Commonly referred to as "text messaging," is a service for sending short messages of up to 160 characters (224 characters if using a 5-bit mode) to mobile devices, including cellular phones, smartphones and PDAs [5].

\section{Voice Call}

A telephone call is a connection over a telephone network between the called party and the calling party [5].

In a study conducted in six West African countries, a third of all pregnant women experienced illness during pregnancy, of whom three percent required hospitalization [4]. Certain pre-existing conditions become more severe during pregnancy. Malaria, HIV/AIDS, anaemia and malnutrition are associated with increased maternal and new-born complications as well as death where the prevalence of these conditions is high [4].

In sub-Saharan Africa, an estimated 900,000 babies die as stillbirths during the last twelve weeks of pregnancy [4]. It is estimated that babies who die before the onset of labour, or antepartum stillbirths, account for two-thirds of all stillbirths in countries where the mortality rate is greater than 22 per 1,000 births nearly all African countries [4]. Antepartum stillbirths have several causes, including maternal infections notably syphilis and pregnancy complications, but systematic global estimates for causes of antepartum stillbirths are not available [4]. New-borns are affected by problems during pregnancy including preterm birth and restricted foetal growth, as well as other fac- tors affecting the baby's development such as congenital infections and foetal alcohol syndrome [4].

\section{Methods}

\section{Study design}

This was a Cross sectional descriptive study.

\section{Study Area}

The Dschang Health district

\section{Study Population}

a) General population: The population of the Dschang health district

b) Source population: The women of procreation age of the Dschang health district

c) Target population: The pregnant women of the Dschang health district

d) Sample population: The pregnant women attending the Dschang district hospital.

\section{Selection criteria}

a) Inclusion Criteria: Pregnant women, at least 18 years

b) Exclusion Criteria: All participants that do not fulfil the above-mentioned criteria

\section{Sample Size}

Using the Epi Info software (descriptive study using random (non-cluster) sampling) to calculate the minimum sample size, using as parameters;

Total pregnant women population size of 11328 in the Dschang health district

Expected frequency: 50\% (since frequency is unknown)

Using a $95 \%$ confidence interval,

The minimum sample size is 372 pregnant women to be included.

\section{Sampling Methods}

The recruitment centre was the Dschang health district hospital. This choice was made from convenience because they account for a great number of prenatal consultations in the Dschang health district. Investigators interviewed all eligible women who had consented to participate in the study until the minimum sample size number was reached.

\section{Method of Data Collection and Analysis}

Data was collected with the use of questionnaires (made available in English and French) orally administered by the investigator after prenatal consultations have been done to the selected women who would have consented to participate in the study. The period of data collection was \& month 1 week (from the $30^{\text {th }}$ of May to the $7^{\text {th }}$ of July), and was done in the Dschang 
district hospital. There are pre organised sessions of prenatal consultations on every Mondays, so special emphasis and mobilisation was doneevery Monday to administer questionnaires to pregnant women. Sampling was performed by convenience. Investigators recruited all eligible women who consented to participate until the minimum sample size number was reached. The questionnaires were then coded and entered in EPI Info 7.1.3.3 and thus analysed. Descriptive and inferential statistical analysis was used.

\section{Data Quality Assessment}

Questionnaires will be checked by the principal investigator for completeness daily by immediate supervisors. After checking for consistency and completeness, the supervisor will submit the filled questionnaire to the principal investigator. Incorrectly filled or missed ones will be sent back to respective data collectors for correction. The principal investigator will again recheck the completed questionnaires to maintain the quality of data.

\section{Ethical Considerations}

Given the fact that this research involves humans (participants, investigator, data collectors) ethical consideration is mandatory. It is for this reason that this protocol will be submitted to the National Ethical Committee in Yaoundé for Ethical Clearance.

\section{Potential Risk Minimisation}

The participants of this research (community individuals of all ages) have some potential risk link to this study which includes: violation of autonomy, rupture of confidentiality on the private data with regards to participants, exploitation of participants and inequality in risk/benefit ratio and also rupture of social equilibrium in community. Such potential risks will be minimised by all the information mentioned in the information notice. This includes:

a. Administering Informed Consent to participants before administering questionnaire,

b. Respecting the autonomy of participants.

c. The data collection tool (questionnaire) will be anonymous, restricting access to data only to those concerned, physical and electronic barriers.

d. Electronic Data will be stored in an apple cloud account accessed only by the principal investigator and the physical questionnaires burned after verification of data

e. Permission will be obtained from District Administration and the hospital administration equally.

Result

\section{Ages of the Pregnant Women}

The average age of women was $26.9(\min 18, \max 40)$ (Figure 1).

\section{Level of Education}

$175(47 \%)$ of the women had for highest level of education the secondary school, and $3(0.81 \%)$ women affirmed that they didn't go to school (Figure 2).
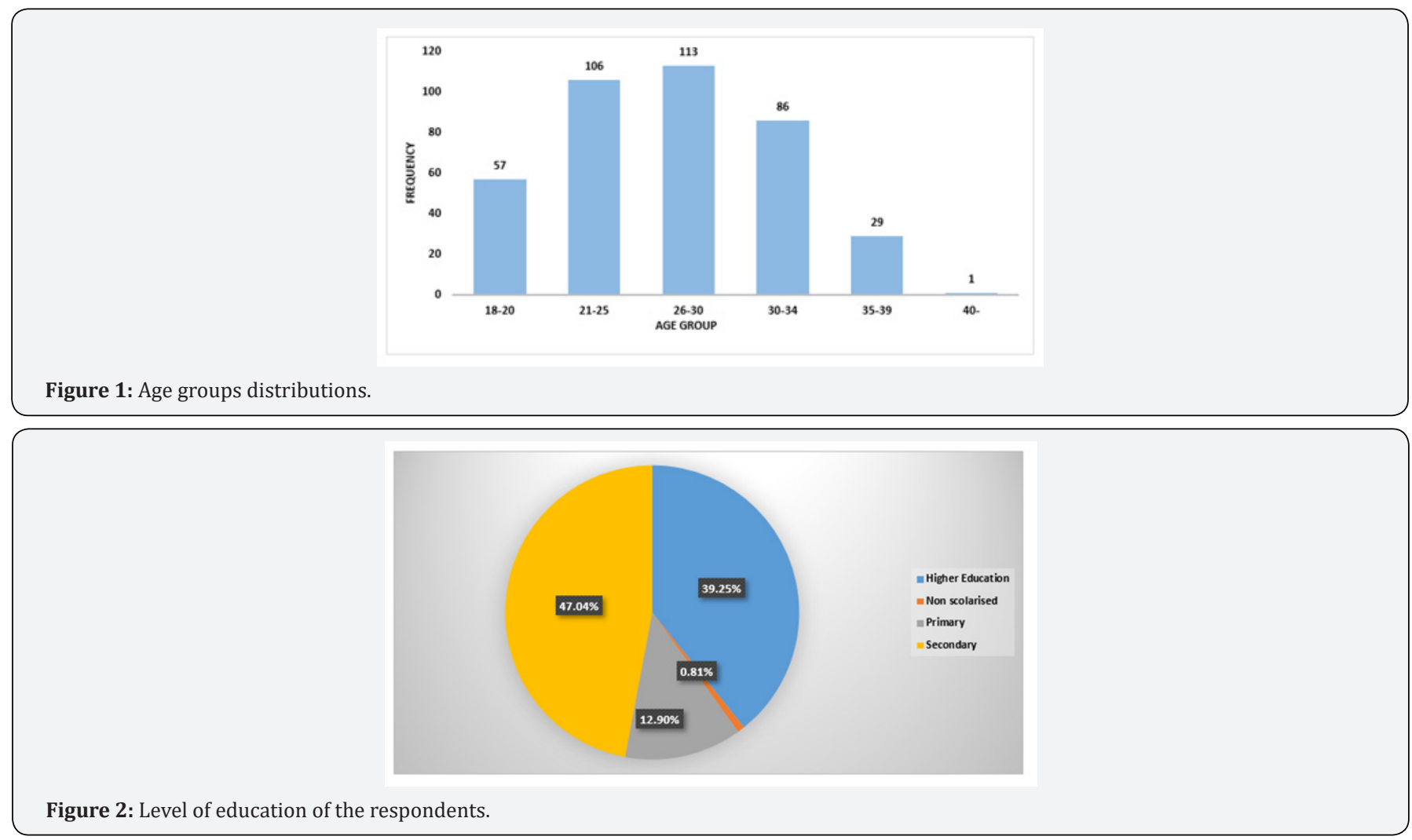


\section{Professions of the Pregnant Women}

$124(33.33 \%)$ women were students (level undifferentiated) and were the highest represented followed by businesswomen
$108(29.03 \%)$. The least represented were farmers, 15(4.03\%)

(Figure 3).

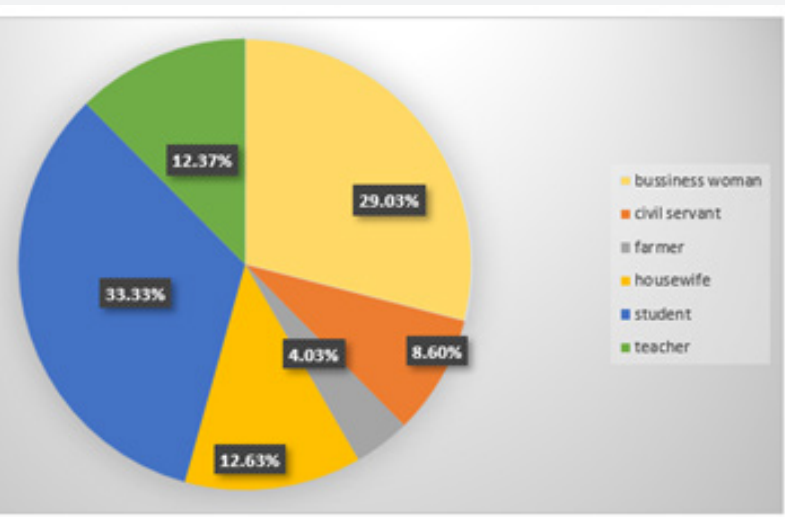

Figure 3: Profession of the respondents.

\section{Marital status of the pregnant Women}

Majority of the women that is $252(67.74 \%)$ were married, $117(31.45 \%)$ of the women affirmed being single, and $3(0.81 \%)$ were devorced.

\section{Religion of the Pregnant Women}

336 (90.32\%) of the women were Christians, 28(7.53\%) were Muslim and $8(2.15 \%)$ affirmed being pagans. Willingness of the pregnant women to pay for the SMS texts or phone calls received, 216 women out of the 335 (64.44\%) that responded willing to receive SMS texts and phone calls affirmed being willing to pay for the service, against 35.52\%. (Figure 4) Distribution of pregnant women willing to pay for service per educational level (Figure 5) better illustrates the distribution of the interviewed women that were willing to pay for the service according to their educational levels while (Figure 6) their distribution per profession. Distribution of the pregnant women that are willing to pay for service according to their marital status. (Figure 7) illustrates the distribution of the pregnant women that are willing to pay for service according to their marital status.

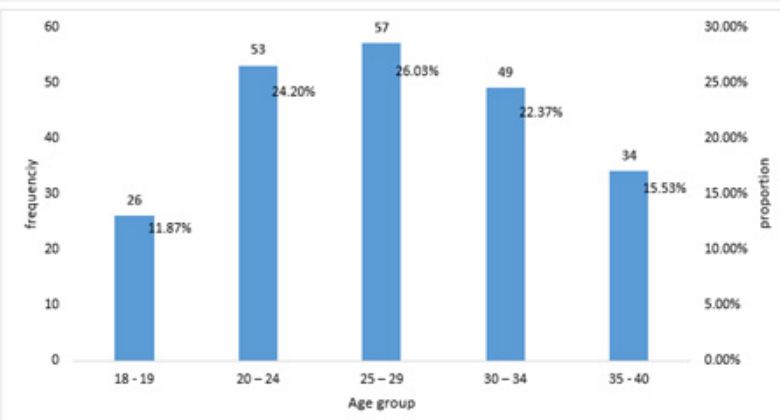

Figure 4: Distribution of willingness to pay for service per age group.

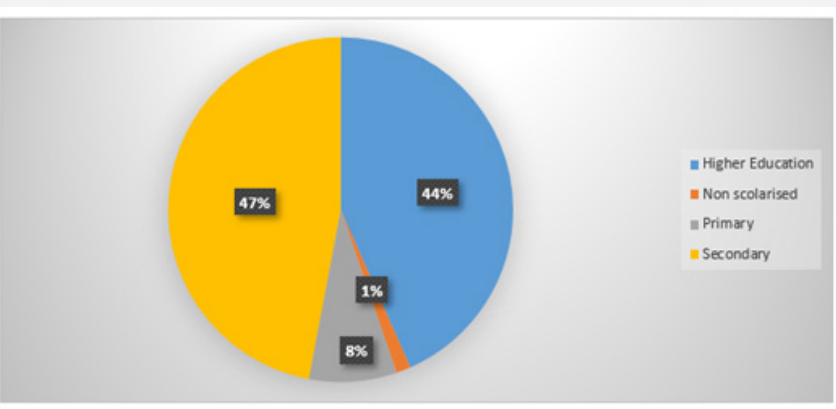

Figure 5:Distribution of pregnant women willing to pay for service per educational level. 


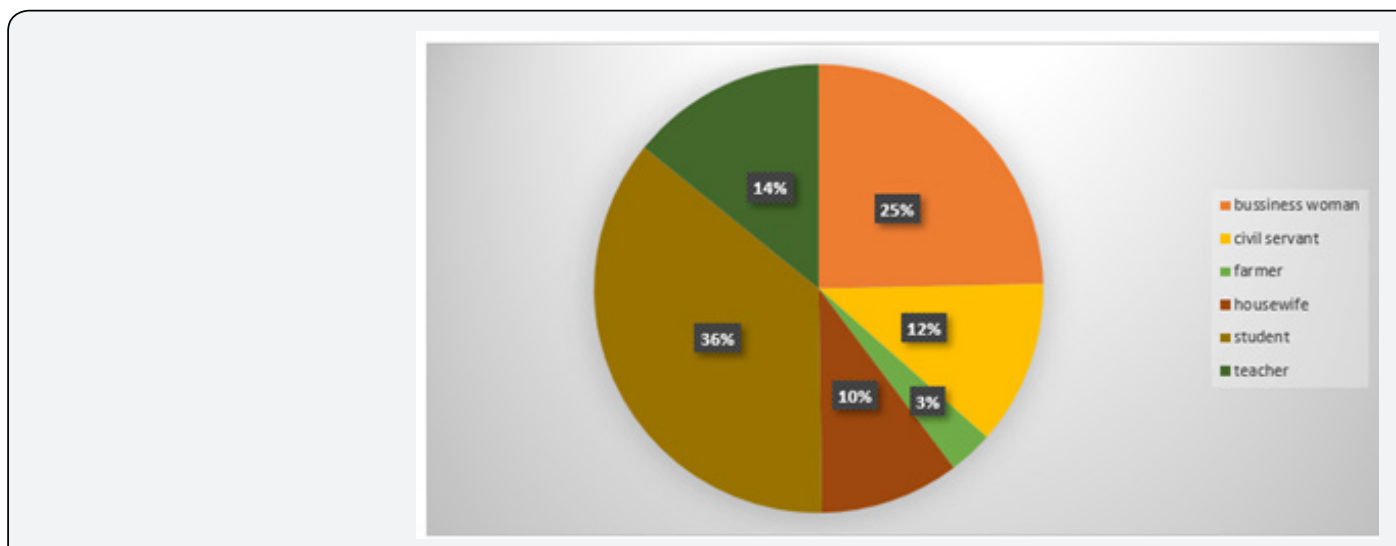

Figure 6:Distribution of pregnant women that were willing to pay for service according to their professions.

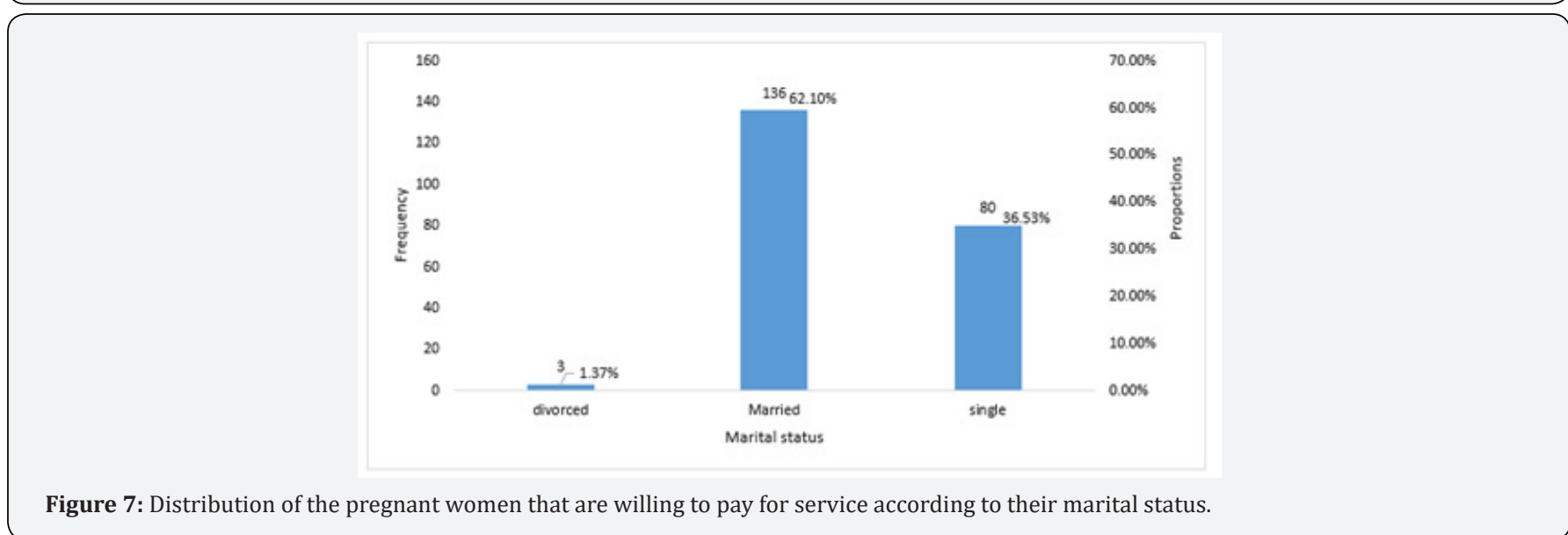

\section{Network Operators}

$310(83.33 \%)$ women affirmed using MTN, followed by Orange, 250 (67.2\%), and last NEXTTEL 105 (28.23\%) women.

\section{Discussion}

The fact that $64.44 \%$ of the women that were interested in the MHealth intervention, were willing to pay for the services, $26.03 \%$ of them from the 25 -29-year-old age group. Also, $36 \%$ of the women willing to pay for the services were students. These results show us that in order to attain a maximum coverage of women in the program, the health service should be free, and toll-free numbers be used for phone calls and thus allow women to freely express their concerns in matters of health.

\section{Conclusion}

This study shows that cell phones would be an acceptable approach to provide pregnancy and postpartum support to women in the Dschang health district, since most women interviewed had access to a cell phone and referred it as a desired and accepted means of communication. In this cell phone approach, free SMS messages and voice calls will be privileged over internet-based interventions. We recommend as follows:

a) Encourage similar studies to be done all over the country and thus have a global view of the issue b) Sends SMS text messages to pregnant women giving them health information

c) Allows pregnant women to send free SMS text messages to the call centre to ask for advice

d) Allows pregnant women to call toll free numbers to seek health advice

e) Sends healthcare advice through SMS texts 3 times a week and in the afternoon or evening.

f) For the uneducated women, use phone calls in local language rather than SMS texts, because these women will likely not read them.

\section{Authors Contributions}

NBA, CNN, VZV, FNS, TBE, FB and SNC conceived and designed the study. NBA implemented the study. NBA conducted data analysis. NBA, CNN, VZV, FNS, TBE, FB and SNC interpreted study results: NBA and NCN wrote the first draft of the manuscript. TBE, FB, NCN and SNC reviewed and corrected the draft manuscript. All authors read and approved the final manuscript.

\section{Previous Studies Have Been on}

a) Postnatal Care. Opportunities for Africa's Newborns. 
b) Giving cell phones to pregnant women and improving services may increase primary health facility utilization

c) Interest of pregnant women in the use of SMS (short message service) text messages for the improvement of perinatal and postnatal care.

\section{What the Study Adds}

a) Pregnant women's access and sources of health information.

b) The use of smartphone and SMS among pregnant women.

\section{Acknowledgement}

We are grateful to all the pregnant women who participated in this research.

\section{References}

1. Eysenbach G (2001) What is e-health? J Med Internet Res 3(2):1-

2. Cormick G, Kim NA, Rodgers A, Gibbons L, Buekens PM, et al. (2012) Interest of pregnant women in the use of SMS (short message service) text messages for the improvement of perinatal and postnatal care. Reprod Health 9(1): 9.

3. Islam MR, Odland JO (2011) Determinants of antenatal and postnatal care visits among indigenous people in Bangladesh: A study of the Mru community. Rural Remote Health 11(2): 1-13.

4. Lincetto O, Mothebesoane AS, Gomez P, Munjanja S (2014) Antenatal Care, pp. 51-62.

5. Torgan C (2011) The mHealth Summit: Local \& Global Converge.

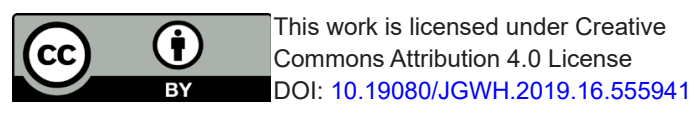

\section{Your next submission with Juniper Publishers will reach you the below assets}

- Quality Editorial service

- Swift Peer Review

- Reprints availability

- E-prints Service

- Manuscript Podcast for convenient understanding

- Global attainment for your research

- Manuscript accessibility in different formats

( Pdf, E-pub, Full Tsext, Audio)

- Unceasing customer service

Track the below URL for one-step submission https://juniperpublishers.com/online-submission.php 